\title{
Schizophrenia and cortical blindness: protective effects and implications for language
}

\author{
Evelina Leivada ${ }^{1}$ and Cedric Boeckx ${ }^{1,2 *}$ \\ ${ }^{1}$ Department of Linguistics, Universitat de Barcelona, Barcelona, Spain \\ ${ }^{2}$ Catalan Institute for Advanced Studies and Research (ICREA), Barcelona, Spain
}

\section{Edited by:}

Mark E. McCourt, North Dakota

State University, USA

Reviewed by:

Jeffrey S. Johnson, North Dakota

State University, USA

Mark E. McCourt, North Dakota

State University, USA

*Correspondence:

Cedric Boeckx, Department of

Linguistics, Universitat de

Barcelona, Gran Via de les Corts

Catalanes 585, 08007 Barcelona,

Spain

e-mail: cedric.boeckx@ub.edu
The repeatedly noted absence of case-reports of individuals with schizophrenia and congenital/early developed blindness has led several authors to argue that the latter can confer protective effects against the former. In this work, we present a number of relevant case-reports from different syndromes that show comorbidity of congenital and early blindness with schizophrenia. On the basis of these reports, we argue that a distinction between different types of blindness in terms of the origin of the visual deficit, cortical or peripheral, is crucial for understanding the observed patterns of comorbidity. We discuss the genetic underpinnings and the brain structures involved in schizophrenia and blindness, with insights from language processing, laying emphasis on the three structures that particularly stand out: the occipital cortex, the lateral geniculate nucleus (LGN), and the pulvinar. Last, we build on previous literature on the nature of the protective effects in order to offer novel insights into the nature of the protection mechanism from the perspective of the brain structures involved in each type of blindness.

Keywords: schizophrenia, vision, protective effects, language, occipital cortex, thalamus

\section{INTRODUCTION}

The literature on psychiatric disorders of the past half a century contains a claim that relates congenital and/or early blindness (CB) to schizophrenia. The absence of reports of schizophrenic patients with $\mathrm{CB}$ has been repeatedly noted, and has led to the claim that $\mathrm{CB}$ confers a protective effect against schizophrenia (Chevigny and Braverman, 1950; Horrobin, 1979; Riscalla, 1980; Sanders et al., 2003; Silverstein et al., 2013a; Postmes et al., 2014). We will refer to this as the "Protection-AgainstSchizophrenia" (PaSZ) hypothesis (Landgraf and Osterheider, 2013). This hypothesis predicts a decreased risk for developing schizophrenia in the blind population (for a schematic representation, see Landgraf and Osterheider, 2013: Figure 1).

The relevant literature includes various phrasings of this idea, ranging from milder claims about $\mathrm{CB}$ serving as a protective factor that reduces the risk to develop schizophrenia (Silverstein et al., 2013a) to stronger claims which imply that this risk is reduced to zero, as in Sanders et al. (2003) "no blind schizophrenics." Regardless of the phrasing one adopts, most studies agree that "there has not been even one reported case of a congenitally blind person who developed schizophrenia" (Silverstein et al., 2013a, p. 1), and yet such cases should exist, on the basis of the joint probability rates calculated in Silverstein et al. (2013b), had it not been that a protection mechanism is in place $^{1}$.

\footnotetext{
${ }^{1}$ Silverstein et al. (2013b) calculated that the joint probability of a person having both CB and schizophrenia, if the two are independent, would be $0.02 \%$ or 2 out of every 10,000. They do now draw the distinction between cortical and peripheral blindness, however they derive their occurrence rates for blindness from Robinson et al. (1987), who reported rates for congenital
}

Although the protective effects of CB have been recently documented (see Landgraf and Osterheider, 2013; Silverstein et al., 2013a on possible cognitive changes as well as neurofunctional and multisensory reorganization effects), certain issues remain to be clarified. It is the aim of this paper to do so. For example, although there is a consensus concerning the fact that case-reports of patients with $\mathrm{CB}$ and schizophrenia have not been uncovered, there exist case-reports of congenital/early deafblindness, due to Usher syndrome, and psychosis (Dammeyer, 2011). Evidently, CB does not offer protection against neurodevelopmental disorders in general. For example, it has been suggested that blind children may present characteristics of infantile autism (see Carvill,

peripheral blindness. Other research that covers both peripheral and cortical blindness suggests that the three leading causes of pediatric blindness in the United States are cortical visual impairment (19\%), retinopathy of prematurity (13\%), and optic nerve hypoplasia (7\%) (Steinkuller et al., 1999). If the leading cause of childhood blindness is cortical visual impairment, one expects that the probability rate of comorbid congenital or early developed cortical blindness with schizophrenia is higher than the probability rate of comorbid congenital or early developed peripheral blindness (say due to retinitis pigmentosa) with schizophrenia. More recent research confirmed these results and ranked cortical visual impairment as the first cause (18\%) of childhood blindness in the United States (Kong et al., 2012). If all causes of $\mathrm{CB}$ excluding that of cortical origin have a prevalence of $82 \%$ in total and if this roughly translates to the probability of comorbid congenital peripheral blindness and schizophrenia being $0.02 \%$ according to Silverstein et al. (2013b), the remaining $18 \%$ approximately corresponds to $0.004 \%$ or 4 out of every 100,000. To put these rates in perspective, Hutchinson-Gilford progeria syndrome is an extremely rare condition ( 1 out of every $8,000,000)$ and yet more than 100 relevant case-reports are found in the literature (Pollex and Hegele, 2004). 
2001 for a review of different studies). People with Usher type I are congenitally deaf, start to lose vision early in life, and may develop schizophrenia (Dammeyer, 2012). The question is why adding deafness to the picture seems to lift the protective benefits and the reasons for this phenomenon are "not clear at present" (Silverstein et al., 2013a, p. 8).

In light of this, the present work aims to:

(i) present cases of co-existence of $\mathrm{CB}$ and schizophrenia, across different syndromes,

(ii) draw attention to a point that is unaddressed in the relevant literature on blindness and schizophrenia and that becomes evident when one reviews the cases mentioned in (i): A distinction between different types of $\mathrm{CB}$ - cortical or peripheral (Dale and Salt, 2008)—established on the basis of the origin of the visual deficit, is crucial in order to explain why the protective effects appear to be lost in deafblindness. Peripheral CB (i.e., arising in the globe, CPB) seems to not confer any protective effects, as the case-reports presented in the next section suggest. Cortical CB (i.e., arising from lesions in the occipital cortex, CCB) presents a less clear picture: our research did not identify a casereport of CCB and schizophrenia, but absence of evidence is not evidence of absence. We suggest that the distinction between CCB and CPB is the key to explain the possible coexistence of schizophrenia and congenital (deaf)blindness in Usher and other syndromes. We further explore the genetic underpinnings of the observed patterns of comorbidity,

(iii) relate schizophrenia and vision to language from the perspective of the brain structures recruited in each of these cognitive domains. Three structures stand out in this context: (a) the visual cortex, located in the posterior pole of the occipital cortex, which in CB individuals is also activated in language processing tasks (Bedny et al., 2011), (b) the lateral geniculate nucleus (LGN), part of the thalamus, which is the key structure related to the processing of information received from the retina, and (c) the thalamic pulvinar, a structure with connections to visual processing (Robinson and Petersen, 1992), but also to language (Llano, 2013) and shape abnormalities in schizophrenia (Thong et al., 2013).

The paper is organized as follows: In Section Cases of Congenital Blindness and Schizophrenia, the distinction between CCB and $\mathrm{CPB}$ is presented and the reasons for assuming it are discussed. The predictions of this distinction are then put in perspective by presenting various case-reports. In Section Genetic Underpinnings and Brain Structures, we explore the genetic parallels of the patterns of comorbidity observed at the phenotypic level. Section The Brain Basis of the Protective Effects addresses the origin of the protective effects in relation to the $\mathrm{CCB} / \mathrm{CPB}$ distinction and the brain basis of each type of blindness. In Section Blindness, Schizophrenia, and Language, the focus is on the brain structures involved in blindness and schizophrenia also with insights from language processing. Section Conclusions concludes.

\section{CASES OF CONGENITAL BLINDNESS AND SCHIZOPHRENIA}

The World Health Organization estimated that in 2002 there were 161 million persons worldwide with visual impairment, with 37 million of them being blind (i.e., visual acuity less than 3/60; see Resnikoff et al., 2004). An estimated 1.4 million were blind children below the age of 15 years (Resnikoff et al., 2004). Other research suggests that these numbers are higher: 259 million persons with visual impairment worldwide, including 42 million blind persons (Dandona and Dandona, 2006). According to the World Health Organization, schizophrenia affects about 24 million people worldwide ${ }^{2}$.

Despite these large numbers of prevalence for each one of the two conditions, it has been argued that patients with $\mathrm{CB}$ seem to be "immune" to schizophrenia, since numerous studies have failed to produce even one well-defined case (Sanders et al., 2003). The aim of this section is to present such cases. We suggest that two factors are necessary in order to delimit the origin of the protective effects: (a) age of blindness onset (congenital/early vs. late) and (b) origin of visual deficit (cortex vs. globe). The PaSZ hypothesis distinguishes between two factors as well: (a) age of blindness onset and (b) degree of visual capacity (i.e., blindness, impairment, normal vision, highly trained vision, etc.). The second factor is indeed relevant in the context of Landgraf and Osterheider (2013), where the relative risk for schizophrenia is related to a continuum of visual capacity toward a "peak risk" (see also Landgraf et al., 2012; Silverstein et al., 2013a). Both sets of factors enter into the relation between schizophrenia and blindness, but in the context of the present discussion the second factor of the PaSZ hypothesis is not so crucial, because we focus on the one edge of the continuum (i.e., blindness).

As the case-reports presented in this section show, only congenital/early cortical blindness - the type of blindness that occurs when bilateral lesions of the occipital cortex deprive the individual from vision (Cummings and Trimble, 2002, p. 110)—seems to confer protective effects. A factor to be taken into consideration is the lack of uniformity in defining age of onset of early blindness. In the context of our study, the distinction between congenital/early vs. late blindness is crucial; therefore, concurring with a long line of research, we take the age of onset of congenital blindness to be birth and the mean age of onset of early blindness to be <5-6 years of age (Arno et al., 2001; Kitada et al., 2013). Following the practice in previous studies (e.g., Silverstein et al., 2013a), these two groups are merged and collectively referred to as $\mathrm{CB}$.

The case-reports and their analysis examined in the present work are the result of extensive text-mining and database searching through PubMed, OMIM, String 9.1 as well as individual journal search for all results retrieved by searches of any combination of the terms "schizophrenia," "psychosis," "congenital/early/childhood/adolescent/late/peripheral/ ocular/cortical/cerebral blindness." Our searches were not constrained by any time frame or language-/ethnic-group restrictions.

Table 1 shows case-reports for three out of four groups of blindness that arise when we combine the two factors: age of onset

\footnotetext{
${ }^{2}$ http://www.who.int/mental_health/management/schizophrenia/en/
} 
Table 1 | Case-reports across types of blindness.

\begin{tabular}{|c|c|c|c|c|}
\hline $\begin{array}{l}\text { Types of } \\
\text { blindness }\end{array}$ & $\begin{array}{l}\text { Late peripheral } \\
\text { blindness (LPB) }\end{array}$ & $\begin{array}{l}\text { Late cortical blindness } \\
\text { (LCB) }\end{array}$ & $\begin{array}{l}\text { Congenital/Early peripheral } \\
\text { blindness (C/EPB) }\end{array}$ & Congenital/Early cortical blindness (C/ECB) \\
\hline Schizophrenia & $\sqrt{ }$ & $\sqrt{ }$ & $\sqrt{ }$ & $?$ \\
\hline Case-reports & Ogden, 1982 & Sonavane et al., 2012 & Weiss et al., 1981 & \\
\hline
\end{tabular}

\begin{tabular}{|c|c|c|c|c|c|c|}
\hline Checkley and Slade, 1979 & $\mathrm{~F}$ & 42 & Retinitis pigmentosa & LPB & Hallucinations & Partial hearing loss \\
\hline Ogden, 1982 & M & $>16$ & Retinitis pigmentosa & LPB & $\begin{array}{l}\text { Hallucinations, } \\
\text { delusions }\end{array}$ & - \\
\hline Engel et al., 1978 & $\mathrm{~F}$ & 20 & Cortex & LCB & Catatonia & $\begin{array}{l}\text { Partial complex status } \\
\text { epilepticus }{ }^{3}\end{array}$ \\
\hline Sonavane et al., 2012 & $\mathrm{~F}$ & 18 & Cortex & LCB & Yes & ECT-induced blindness \\
\hline Sharfstein et al., 1999 & $\mathrm{~F}$ & $>60$ & Cortex & LCB & Yes & $\begin{array}{l}\text { Psychosis is reported, but not } \\
\text { schizophrenia } \\
\text { Severe dementia }\end{array}$ \\
\hline Kerschbaumer, 1943 & $\mathrm{~F}^{4}$ & Birth & Eye under-development & CPB & $\begin{array}{l}\text { No } \\
\text { information }\end{array}$ & 3 cases are reported \\
\hline Kay and Roth, 1961 & $\mathrm{~F}$ & $<82$ & No information & late & Delusions & Partial hearing loss \\
\hline Stewart and Sardo, 1965 & $\mathrm{~F}$ & Birth & No information & Congenital & Catatonia & - \\
\hline
\end{tabular}

(CB vs. late blindness) and origin of the visual deficit (cortical vs. peripheral). Although we identified cases of $\mathrm{CB}$ and schizophrenia, they are all of the CPB type. Our research did not identify a single case of CCB and schizophrenia, although in one case presented in Table 2 (i.e., Stewart and Sardo, 1965) the origin of the deficit is not reported.

In Table 2, the relevant case-reports are presented in further detail. Unless stated otherwise, all case-reports involve a diagnosis of schizophrenia.

Table 2 presents five cases of $\mathrm{CPB}$ and one case of EPB. Starting off from Stewart and Sardo (1965), this is the only case of schizophrenia and CB brought up in Silverstein et al. (2013a) and the validity of the schizophrenia diagnosis is questioned on the basis of absence of psychotic symptoms. However, it can be observed that the patient shows disorganized speech and

\footnotetext{
${ }^{3}$ The patient received two diagnoses: one was catatonic schizophrenia and the other prolonged partial complex status epilepticus. The clinical features of interictal psychosis of epilepsy are often indistinguishable from schizophrenia (Elliott et al., 2009).

${ }^{4}$ Gender information is not explicit, but inferable.
}

grossly disorganized behavior. On this basis, diagnostic criterion A for schizophrenia of DSM-5 (American Psychiatric Association, 2013 ) is met even in the absence of delusions or hallucinations ${ }^{5}$. Second, the patient does seem to show psychotic symptoms that meet DSM-5 diagnostic criteria for catatonia, as these are reviewed in Tandon et al. (2013: Table 1). More specifically, (i) echolalia, (ii) agitation, and (iii) phases of mutism are present in the patient's behavior. The origin of the visual deficit is not explicitly reported, but crucially there is evidence that blindness run in the family. Siblings of the patient are reported to be "afflicted with the same congenital blindness" (Stewart and Sardo, 1965, p. 125). On this basis, we are inclined to assume this is a case of hereditary blindness that involves the globe (i.e., CPB).

\footnotetext{
${ }^{5} \mathrm{~A}$ reviewer draws our attention to the fact that the research criteria for psychosis have changed substantially over time. Of course, numerous changes can be observed when comparing DSM-I (American Psychiatric Association, 1952) and DSM-V. However, it seems that reference to key features such as hallucinations, catatonia, delusional thinking are found across versions, even if emphasis shifts to different diagnostic markers in the course of time. For aspects of the history of DSM and its influences by various traditions, see Andreasen (2007).
} 
The second case-report that is quite explicit on the existence of psychotic symptoms is given in Gobetz (1967). Even if Silverstein et al. (2013a) are right in questioning the schizophrenia diagnosis in Stewart and Sardo (1965), our research has uncovered casestudies where both the psychotic features and the peripheral origin of CB are explicit; the case-report presented in Gobetz (1967) is one example. The cause of CB is optic atrophy. The patient was first hospitalized in the age of 15 and the medical reports make reference to psychotic features such as hallucinations and paranoid thinking. The extensive reference to the contents of her hallucinations leaves no doubt that this is indeed a case of comorbidity between CPB and schizophrenia, with psychotic features present.

Third, Kerschbaumer (1943) presents three cases of schizophrenia and CB. The cause of blindness is eye underdevelopment. Kerschbaumer does not offer the profile of the three congenitally blind patients in terms of psychosis. However, the comments offered in the Conclusion Section (point 9) of that medical report do not offer any reason for challenging the diagnosis of schizophrenia. More specifically, Kerschbaumer draws attention to the need to avoid the misdiagnosis of the catatonic type of schizophrenia as manic-depressive psychosis or the misdiagnosis of early schizophrenia with predominant somatic delusions as psychoneurosis with paranoid ideation. It seems that the diagnoses of schizophrenia have been made with the necessary caution so as to not misrepresent cases falling within the schizophrenia spectrum disorders as schizophrenia. On this basis, we do not have any reason to question the diagnosis of schizophrenia that is given in Kerschbaumer (1943).

Last, Weiss et al. (1981) report a patient who at the age of 6 (upon going to school for the first time) was found to be "almost completely blind" (p. 259) and transferred to a special school. This case is less clear than the ones presented above for two reasons: first, the age of blindness onset is not birth, and second, the patient is almost blind, but not completely. Putting this case-report in the context of the PaSZ hypothesis, almost complete blindness should fall within the low-risk zone for developing schizophrenia identified in Landgraf and Osterheider (2013: Figure 1). With respect to the age factor, the absence of consensus across studies with respect to the age range that corresponds to "early blindness" makes it hard to unambiguously say whether 6 years of age classifies as early or late blindness. Depending on where one puts the limit on the age range, the patient in Weiss et al. (1981) may or may not count as early blind schizophrenic.

Overall, the conclusion to be drawn from these case-reports is that there are cases of comorbidity between congenital and early $\mathrm{PB}$ (i.e., $\mathrm{CPB}$ ) and schizophrenia, but so far no such case has been discovered for congenital or early $\mathrm{CB}$ (i.e., $\mathrm{CCB}$ ) and schizophrenia.

Usher syndrome is in part the ground on which Silverstein et al. (2013a) comment on cases of congenital deafblindness by arguing that it is not clear at present why adding deafness to a case of congenital blindness lifts the protective effects against schizophrenia. As shown in Table 2, not all cases of CB and schizophrenia involve hearing loss. In light of this, deafness cannot be viewed as lifting the protective effect, since the latter appears lifted in cases that deafness is not reported. According to the US National Institute on Deafness and Communication Disorders, Usher syndrome is the most common condition affecting both vision, via retinitis pigmentosa, and hearing ${ }^{6}$. In the literature, one finds numerous reports on the relation between retinitis pigmentosa and schizophrenia (Shukla et al., 1983; McDonald et al., 1998). Recently, an association between usherin and psychotic symptoms has been established on the basis of a genetic analysis of two siblings with Usher syndrome and schizophrenia (Domanico et al., 2012).

Bardet-Biedl syndrome presents a similar picture. It has been referred to as Laurence-Moon-Bardet-Biedl, but LaurenceMoon and Bardet-Biedl are now recognized as separate entities, although not always (Moore et al., 2005). Blindness that is the result of childhood-onset retinitis pigmentosa and schizophrenialike psychosis can co-exist in Bardet-Biedl syndrome (Weiss et al., 1981). The main symptoms of this syndrome are rod-cone dystrophy (atypical retinitis pigmentosa), postaxial polydactyly, mental retardation, hypogonadism, and renal dysfunction (Green et al., 1989; Beales et al., 1999). Language delays have been observed too (Chen et al., 2004; Aloulou et al., 2011). Case-reports indicate comorbidity between (Laurence-Moon-)Bardet-Biedl and schizotypal traits: Delusions of persecution have been reported (O'Mahony, 1954), but also full-blown schizophrenia (Jain and Garg, 1981).

Disrupted-in-Schizophrenial (DISC1) is one of the most frequently discussed susceptibility loci for schizophrenia. It could be described as the standard textbook example of a candidate gene for vulnerability in schizophrenia (e.g., Black and Andreasen, 2011, p. 78). Numerous studies have found positive evidence of association between schizophrenia and genes encoding DISC1-interacting proteins across a variety of ethnic groups (Bradshaw and Porteous, 2012). Crucially, DISC1 plays a "role in radial neuronal migration via anchoring dynein motor-related proteins to the centrosome, including NDEL1, BBS1 and BBS4, two of the proteins mutated in Bardet-Biedl syndrome" (Ishizuka et al., 2011, p. 92; see also Kamiya et al., 2005). In other words, the genetic basis of Bardet-Biedl suggests that this is a syndrome that may manifest comorbidity between schizophrenia and retinitis pigmentosa.

Our review of case-reports in different syndromes suggests that schizophrenia and, more generally, schizotypal features can be found in the $\mathrm{CB}$ population as long as the cause of blindness is found in the globe. The situation is less clear in cases of CCB; in the absence of case-reports that involve both $\mathrm{CCB}$ and schizophrenia, the PaSZ hypothesis (Landgraf and Osterheider, 2013) can be maintained. Aiming to understand the genetic underpinnings of the patterns of comorbidity presented in this section, the next section elaborates on the genetic underpinnings of these patterns and the brain structures involved in the interplay between blindness and schizophrenia.

\footnotetext{
${ }^{6}$ http://www.nidcd.nih.gov/staticresources/health/hearing/FactSheetUsher Syndrome.pdf
} 


\section{GENETIC UNDERPINNINGS AND BRAIN STRUCTURES}

Various case-reports listed above suggest a pattern of comorbidity between retinitis pigmentosa and schizophrenia. This suggests that a potentially interesting connection might be found at the genetic level. In order to investigate the latter, we identified risk genes with high prevalence for each condition, schizophrenia and $\mathrm{CPB}$ (due to either retinitis pigmentosa or anophthalmia). The relevant sets of genes were then fed to String 9.1, a database dedicated to known and predicted protein-protein interactions (Szklarczyk et al., 2011). The resulting networks that represent these interactions integrate information from a variety of sources, "thus acting as a meta-database that maps all interaction evidence onto a common set of genomes and proteins" (Jensen et al., 2009).

\section{RESULTS}

In Figure 1, the relation depicted is between two genes that cause retinitis pigmentosa on the one hand and two genes that are implicated in schizophrenia on the other. The first group consists of $\mathrm{RHO}$ and peripherin 2 (PRPH2); two genes with high prevalence according to Sullivan et al. (2006). The second group involves DISC1 and ERBB4; the latter being the gene with the highest ranking in terms of strength of association with schizophrenia GWAS data sets among the oligodendroglial and myelin related genes (Roussos and Haroutunian, 2014).

The networks are presented in the evidence view. The medium confidence value is 0.400 . Different lines between nodes represent different types of evidence for the reported association (i.e., black is for co-expression, dark blue for co-occurrence, light blue for databases, dark green for neighborhood, light green for text mining, pink for experiments, red for gene fusion, purple for homology). Protein nodes are colored and sized randomly.

In Figure 1, two genes are found to establish the connection between RHO and ERBB4, each of them a gene with connections to schizophrenia and retinitis pigmentosa, respectively: DLG4 and GRK1. DLG4 encodes a member of the membrane-associated guanylate kinase family and has been recently argued to play a role in schizophrenia pathogenesis (Balan et al., 2013). Other studies did not detect any mutations at the protein-coding sequences of DLG4 in schizophrenia populations, but found associations that suggest that the expression of DLG4 is tied to the susceptibility of schizophrenia (Cheng et al., 2010). GRK1 (G-protein-coupled receptor kinase 1) encodes a member of the guanine nucleotidebinding protein ( $G$ protein)-coupled receptor kinase subfamily of the Ser/Thr protein kinase family. It has been associated primarily with night blindness or, else, nyctalopia (Azam et al., 2009), which is a symptom of retinitis pigmentosa (Sharma et al., 2004).

In Figure 2, OTX2, RP1, ANK3, and NRG1 have been added to the group of four genes presented in Figure 1. We think OTX2 stands out because it appears to play a role both in $\mathrm{CPB}$ and schizophrenia. It has been implicated in the development and function of the retina (Bovolenta et al., 1997; Baas et al., 2000; Martinez-Morales et al., 2001) and also in CPB

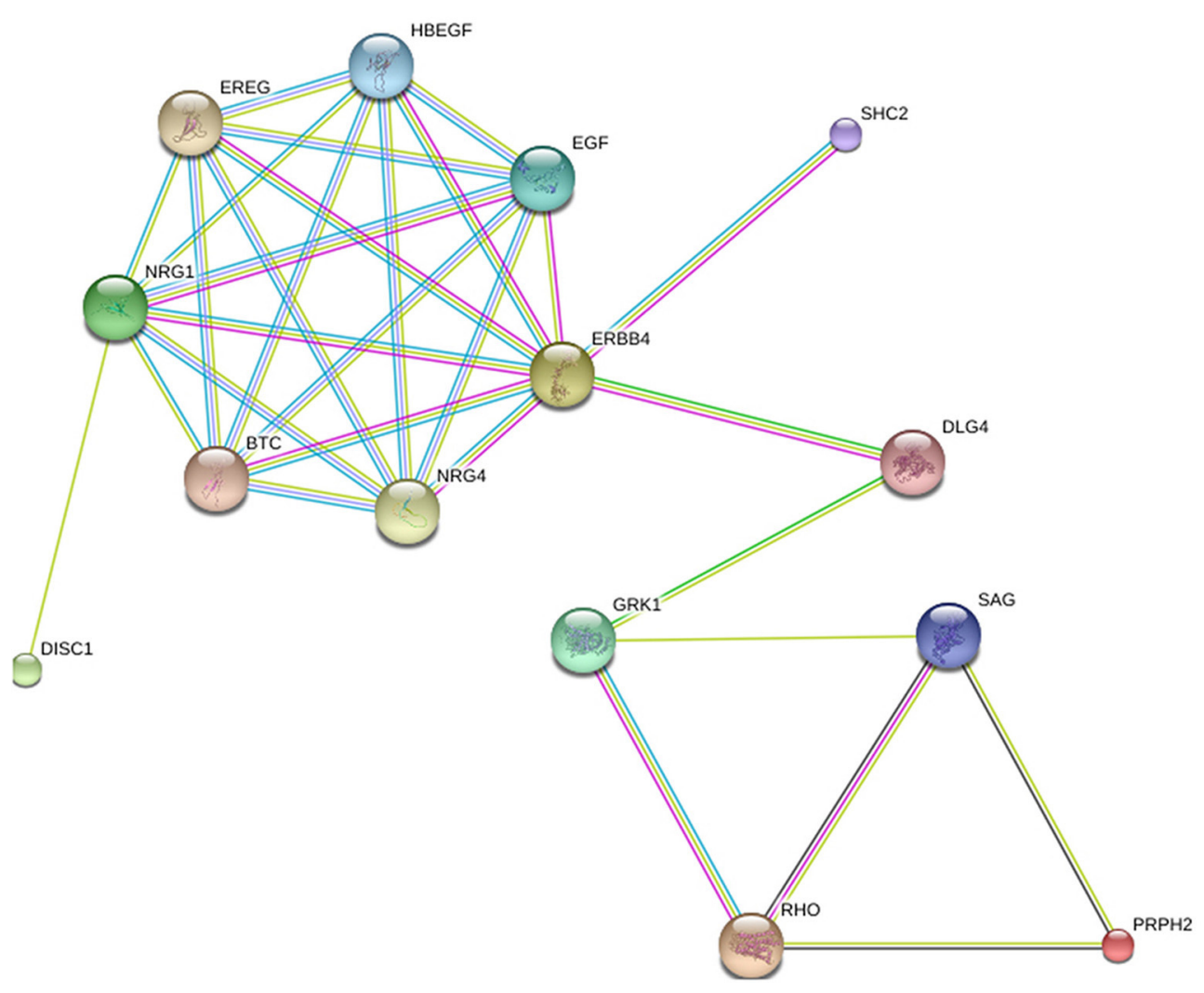

FIGURE 1 | The relation between RHO, PRPH2, DISC1 and ERBB4. Generated by String 9.1. 


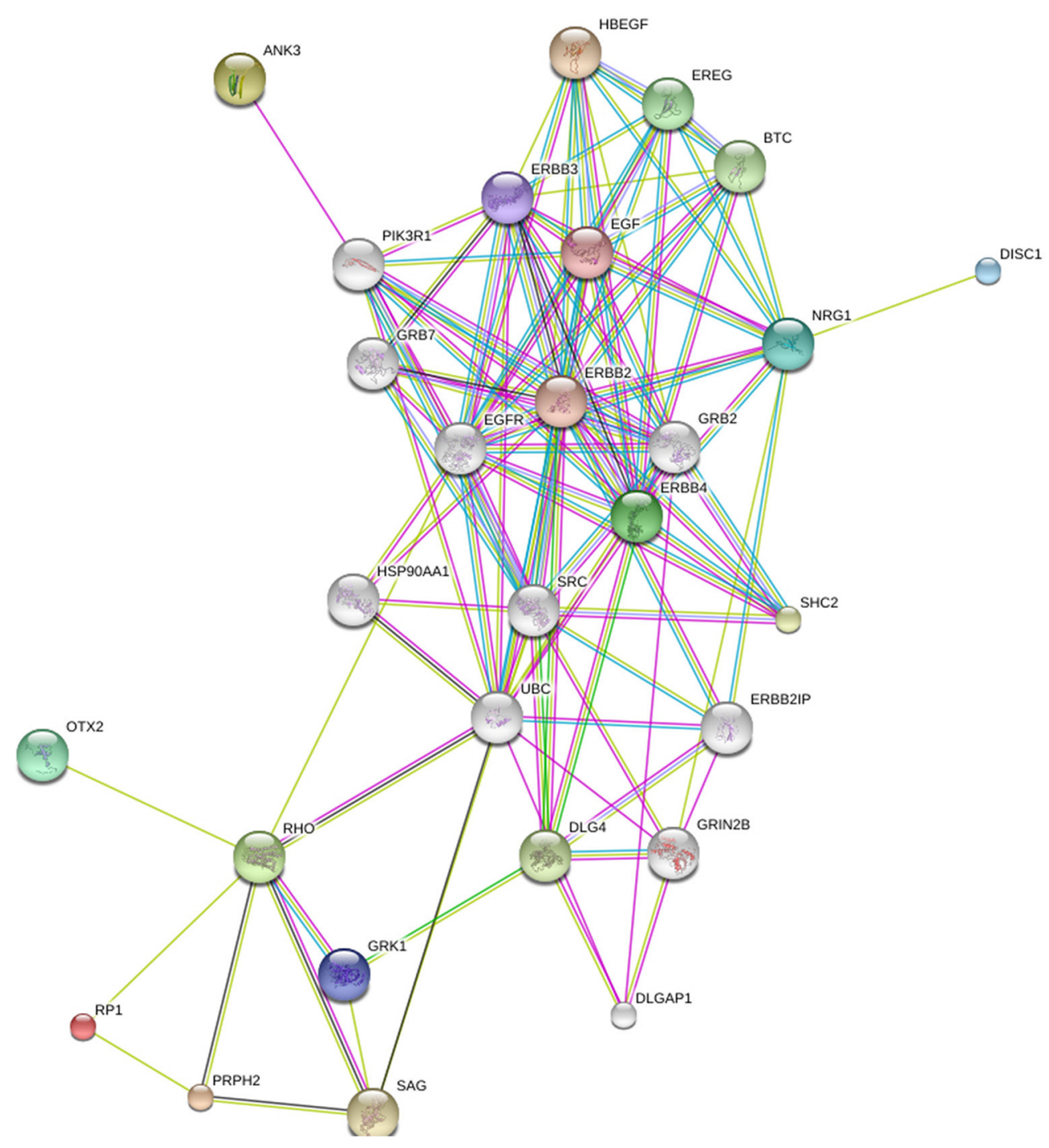

FIGURE 2 | The relation between RP1, RHO, PRPH2, DISC1, ERBB4, ANK3, NRG1, and OTX2. Generated by String 9.1.

due to anophthalmia (Bridge et al., 2009). Otx2 homeoprotein coordinates postnatal parvalbumin (PV) cell development and activates visual cortical plasticity (Sugiyama et al., 2008). Both structural and molecular alterations of PV neurons and protein levels have been found in schizophrenia subjects (Lewis et al., 2012; Glausier et al., 2014). OTX2 is also related to thalamic development (Scholpp and Lumsden, 2010) and "dysfunctional thalamus-related networks" have been reported in schizophrenia (Pinault, 2011). RP1 completes the triad (RHO, PRPH2, RP1) of genes with highest prevalence for retinitis pigmentosa (Sullivan et al., 2006). ANK3 and NRG1 have the second and third highest ranking respectively in terms of strength of association with schizophrenia GWAS data sets among the oligodendroglial and myelin related genes (Roussos and Haroutunian, 2014).

The conclusion to be drawn is that the patterns of comorbidity that are observed between $\mathrm{CPB}$ and schizophrenia at the phenotypic level are related to links between susceptibility loci for the two disorders at the genetic level. In other words, genes that may be implicated in $\mathrm{CPB}$ show multiple connections to genes that are often referred to as schizophrenia candidate genes.

So far, an attempt was made to match the connections observed at the genetic level to patterns of comorbidity between $\mathrm{CPB}$ and schizophrenia observed at the phenotypic level. Given that the highly heterogeneous nature of schizophrenia could be caused by multiple rare alleles (McClellan et al., 2007), the genetic underpinnings of the disease are definitely worth exploring, but provide only a part of the overall picture. Indeed, many recent reviews argue that the dysconnectivity between brain regions is the place to look for the causes that underlie cognitive abnormalities in schizophrenia (Fitzsimmons et al., 2013).

For example, the dysconnectivity between brain regions in schizophrenia has been related to-among others-white matter abnormalities/hyperintensities (Fitzsimmons et al., 2013; Hahn et al., 2014), gray matter volume reduction (Hulshoff Pol et al., 
2002), abnormalities in the anterior cingulate cortex activity (Sanders et al., 2002), "volumetric alterations in prefrontalthalamic-cerebellar gray matter networks" (Rüsch et al., 2007), "aberrant inter-hemispheric connectivity of anterior cortical and sub-cortical brain regions" (Hulshoff Pol et al., 2004), "dysfunctional thalamus-related networks" (Pinault, 2011), and "impaired visual cortical plasticity” (Çavuş et al., 2012). It is interesting to note here that the observed dysconnectivity between brain regions is not restricted to schizophrenia, but rather is a characteristic of psychosis and, as such, it is shared across the (schizophrenia spectrum) disorders that involve psychosis. Individuals with non-clinical psychosis (i.e., healthy individuals that experience occasional psychotic symptoms but are not schizophrenics) show reduced connectivity compared to controls between regions in all of the networks and the thalamus (Orr et al., 2014). Positive symptoms were associated with "increased connectivity between the cingulo-opercular network and visual cortex" (Orr et al., 2014). In sum, there is growing support for the existence of aberrations in connectivity between different networks and brain structures in individuals with psychosis. Two of the structures recurrently showing up in the relevant literature are the visual cortex and the thalamus, a point to which we now turn.

\section{THE BRAIN BASIS OF THE PROTECTIVE EFFECTS}

As the presentation of different syndromes in Section Cases of Congenital Blindness and Schizophrenia suggested, a link seems to exist between visual dysfunction of peripheral origin and schizophrenia. This relation is evidenced also in first-degree relatives of patients with schizophrenia (e.g., in forms of eye movement dysfunction; Calkins et al., 2008). The aim of this section is to explore the different brain bases of the two types of blindness, $\mathrm{CCB}$ and $\mathrm{CPB}$, and offer an explanation as to why the protected effects seem conferred to a greater degree by the former, since we do find cases of comorbidity of the latter with schizophrenia.

One explanation as to why the protective effects appear to be granted differently in CCB and CPB could be related to the fact that the two types of blindness have a different brain basis. In other words, the protective effects could be the outcome of impaired connectivity between brain areas disrupted differentially in CCB and CPB. The basis of this discussion lies in the idea that the protective effects are not the result of blindness per $s e$, but rather of brain changes that occur secondary to blindness (Silverstein et al., 2013a, p. 1). Naturally, since the two types of blindness, cortical and peripheral, have a different brain basis, the subsequent brain changes may not be uniform, and a modulation of the protection mechanism may be allowed across the two.

Importantly, the modulation of the protection mechanism that we assume to exist is compatible with the idea in Silverstein et al. (2013a) that a cluster of perceptual and cognitive functions, which are impaired in schizophrenia and significantly enhanced in congenital blindness, might offer protective effects (see also Cattaneo et al., 2008; Cattaneo and Vecchi, 2011 for reviews of enhanced perceptual skills in the CPB population). Because the enhancement comes from brain changes secondary to experiencing the world without vision, it is highly likely that the protective effects are to be found in both $\mathrm{CPB}$ and $\mathrm{CCB}$, because in both conditions the world is experienced without vision. The modulation we propose boils down to the protection mechanism being further reinforced in cases of CCB due to the brain basis of this condition.

The idea of perceptual organization dysfunction often manifested in schizophrenia through object fragmentation is relevant in this respect (Uhlhaas and Silverstein, 2005; Silverstein and Keane, 2011a). This idea supports a view of schizophrenia as "fundamentally a cognitive (i.e., information processing) disorder" (Silverstein et al., 2013a, p. 1). The brain structure that appears to be most critical for information processing is the thalamus; abnormal thalamic structures and dysfunctional thalamus-related networks have been repeatedly implicated in schizophrenia (Andreasen, 1997; Pinault, 2011). The CCB/CPB distinction is highly relevant in this context. In cases of $\mathrm{CPB}$ due to anophthalmia, significant white matter volume reductions have been observed around the thalamus (Bridge et al., 2009). The LGN in the anophthalmic subjects was found to be abnormal, compared to the controls; however, the connectivity between the LGN and the primary visual cortex did not differ between the two populations (Bridge et al., 2009). The conclusion drawn was that "these findings could imply a rewiring of brain function in the occipital lobe at a subcortical in addition to or instead of at a cortical level” (p. 3479).

In another study, the optic pathways of patients with $\mathrm{CPB}$ showed atrophy or hypoplasia in 7 of the 12 patients $(58 \%)$, the optic nerve in 4 patients, the chiasm in 4 patients and the tract in 2 patients, however in all 12 patients the visual cortex appeared morphologically normal (Breitenseher et al., 1998). The picture is different in cases of CCB, where subcortical structures are intact and have been reported to be activated for eye contact (Burra et al., 2013). This subcortical neural pathway, which leads from the retina to the superior colliculus, to the pulvinar and then to the amygdala, permits processing of potentially threatening stimuli (Skuse, 2006). Observing first that schizophrenia has been described as a processing disorder that is related to dysfunctional thalamic networks and second that the protective effects appear to be limited to the type of blindness that does not imply thalamic abnormalities, it is possible that the protective effects could boil down to functions of the-rewired in the case of $\mathrm{CB}$ - subcortical (thalamic) structures that are largely intact in $\mathrm{CCB}$, but not in CPB.

Usually the language faculty is not part of discussions on the relation between blindness and schizophrenia. However observing the interesting connections between blindness and language noted in Silverstein et al. (2013a), the next section builds on the insights offered in that work in order to discuss the "blindnessschizophrenia-language" triangle from the perspective of the brain structures involved in vision, schizophrenia, and language processing.

\section{BLINDNESS, SCHIZOPHRENIA, AND LANGUAGE}

Yoon et al. (2013) start their review of studies of visual perception in schizophrenia by drawing our attention to the "wide variety of processes that have implicated abnormalities at various levels of the visual system, from the retina (Balogh et al., 2008) to higher-order extrastriate visual cortex (Butler et al., 2008).” The intricate relation between (absent, present, and impaired) vision and schizophrenia has been thoroughly reviewed recently (e.g., 
Landgraf and Osterheider, 2013; Silverstein et al., 2013a; Yoon et al., 2013) and the present section does not need to address this relation further. Instead, the aim is to add another factor to the equation: language.

The relation between schizophrenia and language has at times been approached in terms of the former being a disruption of the latter. Thought disorder has been described as "the most studied symptom of a much-studied disorder, schizophrenia" (McKenna and Oh, 2005, p. ix). There is a long tradition that views thought disorder as a disorder of language (Kleist, 1914) or, in more nuanced terms, as language abnormality making a contribution to the phenomenon of thought disorder in schizophrenia (McKenna and Oh, 2005, p. 99). Although there is no doubt that some aspects of language may be disrupted in schizophrenia, it is crucial to realize that these linguistic abnormalities might be due to a cognitive abnormality manifested in a linguistic dress (for example, the increased use of second person pronouns in schizophrenia that (Watson et al., 2012) report could be due to perturbations in non-egocentric referencing which are demonstrated in non-linguistic tasks, e.g., Landgraf et al., 2010).

Silverstein et al. (2013a) provide a brief overview of language delays in CB schizophrenics and they make a crucial observation. Noticing abnormalities related to language processing in CB children (Perez-Pereira and Conti-Ramsden, 1999), they propose that "[o]ne possible consequence of these is a reduction in the risk of developing disordered thought, which is commonly seen in schizophrenia. For example, many thought-disordered patients with schizophrenia have a tendency toward overabstraction and overinclusion in their thinking, as well as overly elaborated (and more easily primed) semantic networks (Siekmeier and Hoffman, 2002; Lerner et al., 2012)" (p. 3). CB children have the opposite tendency in being "characterized by a lack of over-generalization of concepts and categories, and a reduced number of word inventions (Andersen et al., 1984, 1993)” (p. 4).

One conclusion to be drawn from this state of affairs is that $\mathrm{CB}$ controls or suppresses the overabstraction tendencies and the abnormal associative processes (i.e., fragmentation) that Lerner et al. (2012) report in relation to patients with schizophrenia. This control can be thought of as part of the protective effects that CB confers. Such an observation makes the "blindnessschizophrenia-language" triangle worth analyzing further, mainly from the perspective of brain structures identified in the previous section, which is something that has not been done so far in the literature on blindness and schizophrenia.

Back to vision, Amedi et al. (2005) describe the process of seeing along the following lines: "Focused light landing on the retina causes neuronal signals to leave the eye through the optic nerve; those signals are sent via the LGN of the thalamus to the occipital cortex, where the majority of visual processing takes place" (p. 306). There is experimental support for the claim that some brain areas switch functions; one of them is the function of the occipital cortex in the blind population. More specifically, the visual cortex of peripherally blind subjects is recruited for the processing of tactile and auditory information (Sadato et al., 1996, 1998; Pascual-Leone and Hamilton, 2001). Also, occipital cortex activation has been reported during speech/language processing and semantic-judgment tasks (Roder et al., 2002; Burton,
2003; Pascual-Leone et al., 2005; Bedny et al., 2011). It has been suggested that recruitment of visual circuits for language processing depends on the age factor: the presence of blindness during childhood (Bedny et al., 2012).

With respect to language processing skills, patients with $\mathrm{CPB}$ are significantly better than sighted individuals in ultra-fast speech perception. In a recent experiment, among the areas that showed high activation were the right-hemispheric primary visual cortex, the contralateral fusiform gyrus, and the bilateral pulvinar (Dietrich et al., 2013). The fusiform gyrus is argued to subserve face perception (Kanwisher et al., 1997), an ability impaired in schizophrenia (Chen et al., 2008). Viewing blindness, schizophrenia, and language altogether, from the perspective of the brain structures that seem to play a more leading role compared to others, three structures figure prominently: (a) the visual cortex, located in the posterior pole of the occipital cortex, (b) the LGN, and (c) the pulvinar. These three structures are intimately interconnected in visual processing: The primary visual cortex receives input via LGN, while the lateral pulvinar nucleus projects to the visual cortex as well and "is able to powerfully control and gate information outflow" from the primary visual cortex (Purushothaman et al., 2012, p. 905).

With respect to schizophrenia, all three structures stand out as key points for abnormalities. There is a variety of studies reporting impaired plasticity, dysfunctional network connectivity, and a disturbed shape due to disrupted corticogenesis in relation to the visual cortex of schizophrenic individuals (Çavuş et al., 2012; Schultz et al., 2013; Ford et al., 2014). With respect to the two thalamic structures discussed here, LGN is one of the structures where Protocadherin-11 (PCDH11) is expressed in the neonatal brain (Matsunaga et al., 2013, Table 1). Crucially, this gene has been related to psychosis (Crow, 2013). The volume of LGN was found to be increased in patients suffering from mood disorders such as major depression or bipolar disorder with psychotic features, although this increase was not found in the schizophrenic group (Dorph-Petersen et al., 2008). True, other studies relate LGN to abnormalities distinct to schizoaffective disorder (Smith et al., 2011). However, when putting these findings in the bigger picture, one should take into account that the dividing lines among schizophrenia spectrum disorders are not always clear. Overall, it seems that the population may vary across studies, however it consistently targets a disorder that involves psychosis. Lastly, thalamic shape abnormalities in schizophrenics have been found also in regions related to pulvinar and medial dorsal nuclei (Thong et al., 2013).

In the case of language, the role of the visual cortex in language tasks has been demonstrated across studies, as discussed earlier in this section. Reports on the relation between language and the thalamus date back more than a century (Dejerine and Roussy, 1906). Recently, the thalamus was argued to be central to human cognition, and particularly to language, on the basis of a new candidate gene set whose members are related both to the development of the thalamus and to language-associated cognitive disorders (Boeckx and Benítez-Burraco, 2014). With respect to LGN, PCDH11 is argued to play a critical role in aspects of human cognition related to language (Crow, 2002; Priddle and Crow, 2009, 2013). Moreover, a number of reviews points to a 
possible involvement of the thalamus in manipulations of lexical information and naming processes, laying emphasis on the role of the pulvinar (Hebb and Ojemann, 2013; Llano, 2013).

\section{CONCLUSIONS}

It has been argued that vision science can significantly advance our understanding of schizophrenia (Silverstein and Keane, 2011b). The aim of this work was to explore aspects of the relation between absent vision and schizophrenia. The departure point was the claim that $\mathrm{CB}$ confers a protective effect against schizophrenia; a claim based on the absence of case-reports of comorbid CB and schizophrenia (Chevigny and Braverman, 1950; Horrobin, 1979; Riscalla, 1980; Sanders et al., 2003; Landgraf and Osterheider, 2013; Silverstein et al., 2013a; Postmes et al., 2014). We presented a number of relevant case-reports and showed that all fall into a specific type of blindness, that of peripheral origin. On this basis, we suggested that the distinction between different types of blindness in terms of the origin of the visual deficit is crucial for understanding both the observed patterns of comorbidity and the nature of the protective effects. Building on previous work on the topic (Silverstein et al., 2013a), we argued in favor of a modulation of the protection mechanism in cases of congenital/early cortical blindness.

In our research we did not manage to uncover any cooccurrence of congenital/early cortical blindness and schizophrenia. Although we acknowledge, together with Silverstein et al. (2013b) and Landgraf and Osterheider (2013) that absence of evidence is not evidence of absence, we are inclined to assume on the basis of the prevalence rates of each condition, that some casereports should have been identified, had it not been for some protective effects being in place. It is likely that future research on the topic will shed more light on the nature of the protective mechanism, possibly clarifying whether the protective effect is confined to schizophrenia or extends to schizotypal traits more broadly.

\section{ACKNOWLEDGMENTS}

We thank the members of the Biolinguistics Initiative Barcelona, for their constructive comments. The present work was made possible through a Marie Curie International Reintegration Grant from the European Union (PIRG-GA-2009-256413), research funds from the Fundació Bosch i Gimpera, and a grant from the Spanish Ministry of Economy and Competitiveness (FFI-201020634).

\section{REFERENCES}

Aloulou, H., Cheikhrouhou, H., Belguith, N., Ben Ameur, S., Ben Mansour, L., Chabchoub, I., et al. (2011). Bardet-Biedl syndrome in the child. A study about 11 cases. Tunis. Med. 89, 31-36.

Amedi, A., Merabet, L. B., Bermpohl, F., and Pascual-Leone, A. (2005). The occipital cortex in the blind. Lessons about plasticity and vision. Curr. Dir. Psychol. Sci. 14, 306-311. doi: 10.1111/j.0963-7214.2005.00387.x

American Psychiatric Association. (1952). Diagnostic and Statistical Manual of Mental Disorders-(DSM-I). Washington, DC: American Psychiatric Association.

American Psychiatric Association. (2013). Diagnostic and Statistical Manual of Mental Disorders-(DSM-V). Washington, DC: American Psychiatric Association.
Andersen, E. S., Dunlea, A., and Kekelis, L. S. (1984). Blind children's language: resolving some differences. J. Child Lang. 11, 645-664. doi: 10.1017/S0305000900006000

Andersen, E. S., Dunlea, A., and Kekelis, L. S. (1993). The impact of input: language acquisition in the visually impaired. First Lang. 13, 23-49. doi: $10.1177 / 014272379301303703$

Andreasen, N. C. (1997). The role of the thalamus in schizophrenia. Can. J. Psychiatry 42, 27-33.

Andreasen, N. C. (2007). DSM and the death of phenomenology in America: an example of unintended consequences. Schizophr. Bull. 33, 108-112. doi: $10.1093 / \mathrm{schbul} / \mathrm{sbl} 054$

Arno, P., De Volder, A. G., Vanlierde, A., Wanet-Defalque, M. C., Streel, E., and Robert, A. (2001). Occipital activation by pattern recognition in the early blind using auditory substitution for vision. Neuroimage 13, 632-645. doi: 10.1006/nimg.2000.0731

Azam, M., Collin, R. W. J., Khan, M. I., Shah, S. T., Qureshi, N., Ajmal, M., et al. (2009). A novel mutation in GRK1 causes Oguchi disease in a consanguineous Pakistani family. Mol. Vis. 15, 1788-1793.

Baas, D., Bumsted, K. M., Martinez, J. A., Vaccarino, F. M., Wikler, K. C., and Barnstable, C. J. (2000). The subcellular localization of OTX2 is cell-type specific and developmentally regulated in the mouse retina. Mol. Brain Res. 78, 26-37. doi: 10.1016/S0169-328X(00)00060-7

Balan, S., Yamada, K., Hattori, E., Iwayama, Y., Toyota, T., Ohnishi, T., et al. (2013). Population-specific haplotype association of the postsynaptic density gene DLG4 with schizophrenia, in family-based association studies. PLoS ONE 8:e70302. doi: 10.1371/journal.pone.0070302

Balogh, Z., Benedek, G., and Kéri, S. (2008). Retinal dysfunctions in schizophrenia. Prog. Neuropsychopharmacol. Biol. Psychiatry 32, 297-300. doi: 10.1016/j.pnpbp.2007.08.024

Beales, P. L., Elcioglu, N., Woolf, A. S., Parker, D., and Flinter, F. A. (1999). New criteria for improved diagnosis of Bardet-Biedl syndrome: results of a population survey. J. Med. Genet. 36, 437-446.

Bedny, M., Pascual-Leone, A., Dodell-Feder, D., Fedorenko, E., and Saxe, R. (2011). Language processing in the occipital cortex of congenitally blind adults. Proc. Natl. Acad. Sci. U.S.A. 108, 4429-4434. doi: 10.1073/pnas.1014818108

Bedny, M., Pascual-Leone, A., Dravida, S., and Saxe, R. (2012). A sensitive period for language in the visual cortex: distinct patterns of plasticity in congenitally versus late blind adults. Brain Lang. 122, 162-170. doi: 10.1016/j.bandl.2011.10.005

Black, D. W., and Andreasen, N. C. (2011). Introductory Textbook of Psychiatry, 5th Edn. Arlington, VA: American Psychiatric Publishing.

Boeckx, C., and Benítez-Burraco, A. (2014). The shape of the human languageready brain. Front. Psychol. 5:282. doi: 10.3389/fpsyg.2014.00282

Bovolenta, P., Mallamaci, A., Briata, P., Corte, G., and Boncinelli, E. (1997). Implication of OTX2 in pigment epithelium determination and neural retina differentiation. J. Neurosci. 17, 4243-4252.

Bradshaw, N. J., and Porteous, D. J. (2012). DISC1-binding proteins in neural development, signalling and schizophrenia. Neuropharmacology 62, 1230-1241. doi: 10.1016/j.neuropharm.2010.12.027

Breitenseher, M., Uhl, F., Prayer Wimberger, D., Deecke, L., Trattnig, S., and Kramer, J. (1998). Morphological dissociation between visual pathways and cortex: MRI of visually-deprived patients with congenital peripheral blindness. Neuroradiology 40, 424-427. doi: 10.1007/s002340050616

Bridge, H., Cowey, A., Ragge, N., and Watkins, K. (2009). Imaging studies in congenital anophthalmia reveal preservation of brain architecture in "visual" cortex. Brain 132, 3467-3480. doi: 10.1093/brain/awp279

Burra, N., Hervais-Adelman, A., Kerzel, D., Tamietto, M., de Gelder, B., and Pegna, A. J. (2013). Amygdala activation for eye contact despite complete cortical blindness. J. Neurosci. 33, 10483-10489. doi: 10.1523/JNEUROSCI.3994-12.2013

Burton, H. (2003). Visual cortex activity in early and late blind people. J. Neurosci. 23, 4005-4011.

Butler, P. D., Tambini, A., Yovel, G., Jalbrzikowski, M., Ziwich, R., Silipo, G., et al. (2008). What's in a face? Effects of stimulus duration and inversion on face processing in schizophrenia. Schizophr. Res. 103, 283-292. doi: 10.1016/j.schres.2008.03.007

Calkins, M. E., Iacono, W. G., and Ones, D. S. (2008). Eye movement dysfunction in first-degree relatives of patients with schizophrenia: a meta-analytic evaluation of candidate endophenotypes. Brain Cogn. 68, 436-461. doi: 10.1016/j.bandc.2008.09.001 
Carvill, S. (2001). Sensory impairments, intellectual disability and psychiatry. J. Intellect. Disabil. Res. 45, 467-483. doi: 10.1046/j.1365-2788.2001.00366.x

Cattaneo, Z., and Vecchi, T. (2011). Blind Vision. Cambridge, MA: MIT Press. doi: 10.7551/mitpress/9780262015035.001.0001

Cattaneo, Z., Vecchi, T., Cornoldi, C., Mammarella, I., Bonino, D., Ricciardi, E., et al. (2008). Imagery and spatial processes in blindness and visual impairment. Neurosci. Biobehav. Rev. 32, 1346-1360. doi: 10.1016/j.neubiorev.2008.05.002

Çavuş, I., Reinhart, R. M., Roach, B. J., Gueorguieva, R., Teyler, T. J., Clapp, W. C. et al. (2012). Impaired visual cortical plasticity in schizophrenia. Biol. Psychiatry 71, 512-520. doi: 10.1016/j.biopsych.2012.01.013

Checkley, S. A., and Slade, A. P. (1979). Blindness and schizophrenia. Lancet 313, 730-731. doi: 10.1016/S0140-6736(79)91188-7

Chen, C. L., Chung, C. Y., Cheng, P. T., Chen, C. H., and Chen, M. H. (2004). Linguistic and gait disturbance in a child with Laurence-Moon-Biedl syndrome: left temporal and parietal lobe hypoplasia. Am. J. Phys. Med. Rehabil. 83, 69-74. doi: 10.1097/01.PHM.0000091989.01773.1C

Chen, Y., Norton, D., Ongur, D., and Heckers, S. (2008). Inefficient face detection in schizophrenia. Schizophr. Bull. 34, 367-374. doi: 10.1093/schbul/sbm071

Cheng, M. C., Lu, C. L., Luu, S. U., Tsai, H. M., Hsu, S. H., Chen, T. T., et al. (2010). Correction: genetic and functional analysis of the dlg4 gene encoding the postsynaptic density protein 95 in schizophrenia. PLoS ONE 5:e15107. doi: 10.1371/ journal.pone.0015107

Chevigny, H., and Braverman, S. (1950). The Adjustment of the Blind. New Haven, CT: Yale University Press.

Crow, T. J. (2002). Handedness, language lateralisation and anatomical asymmetry: relevance of protocadherin XY to hominid speciation and the aetiology of psychosis: point of view. Br. J. Psychiatry 181, 295-297. doi: 10.1192/bjp.181. 4.295

Crow, T. J. (2013). The XY gene hypothesis of psychosis: Origins and current status. Am. J. Med. Genet. Part B 162B, 800-824. doi: 10.1002/ajmg.b.32202

Cummings, J. L., and Trimble, M. R. (2002). Concise Guide to Neuropsychiatry and Behavioral Neurology, 2nd Edn. Arlington, VA: American Psychiatric Publishing.

Dale, N., and Salt, A. (2008). Social identity, autism and visual impairment (VI) in the early years. Br. J. Vis. Impair. 26, 135-146. doi: 10.1177/0264619607 088282

Dammeyer, J. (2011). Mental and behavioural disorders among people with congenital deafblindness. Res. Dev. Disabil. 32, 571-575. doi: 10.1016/j.ridd.2010.12.019

Dammeyer, J. (2012). Children with Usher syndrome: mental and behavioral disorders. Behav. Brain Funct. 8:16. doi: 10.1186/1744-9081-8-16

Dandona, L., and Dandona, R. (2006). What is the global burden of visual impairment? BMC Med. 4:6 doi: 10.1186/1741-7015-4-6

Dejerine, J., and Roussy, G. (1906). Thalamic syndrome. Rev. Neurol. France 14, 521-532.

Dietrich, S., Hertrich, I., and Ackermann, H. (2013). Ultra-fast speech comprehension in blind subjects engages primary visual cortex, fusiform gyrus, and pulvinar - a functional magnetic resonance imaging (fMRI) study. BMC Neurosci. 14:74. doi: 10.1186/1471-2202-14-74

Domanico, D., Fragiotta, S., Trabucco, P., Nebbioso, M., and Vingolo, E. M. (2012). Genetic analysis for two Italian siblings with Usher Syndrome and schizophrenia. Case Rep. Ophthalmol. Med. 2012, 1-6. doi: 10.1155/2012/ 380863

Dorph-Petersen, K. A., Caric, D., Saghafi, R., Zhang, W., Sampson, A. R., and Lewis, D. A. (2008). Volume and neuron number of the lateral geniculate nucleus in schizophrenia and mood disorders. Acta Neuropathol. 117, 369-384. doi: 10.1007/s00401-008-0410-2

Elliott, B., Joyce, E., and Shorvon, S. (2009). Delusions, illusions and hallucinations in epilepsy: 2. Complex phenomena and psychosis. Epilepsy Res. 85, 172-186. doi: 10.1016/j.eplepsyres.2009.03.017

Engel, J. Jr., Ludwig, B. I., and Fetell, M. (1978). Prolonged partial complex status epilepticus: EEG and behavioral observations. Neurology 28, 863-869. doi: 10.1212/WNL.28.9.863

Fitzsimmons, J., Kubicki, M., and Shenton, M. E. (2013). Review of functional and anatomical brain connectivity findings in schizophrenia. Curr. Opin. Psychiatry 26, 172-187. doi: 10.1097/YCO.0b013e32835d9e6a

Ford, J. M., Palzes, V. A., Roach, B. J., Potkin, S. G., van Erp, T. G., Turner, J. A., et al. (2014). Visual hallucinations are associated with hyperconnectivity between the amygdala and visual cortex in people with a diagnosis of schizophrenia. Schizophr. Bull. doi: 10.1093/schbul/sbu031. [Epub ahead of print].
Glausier, J. R., Fish, K. N., and Lewis, D. A. (2014). Altered parvalbumin basket cell inputs in the dorsolateral prefrontal cortex of schizophrenia subjects. Mol. Psychiatry 19, 30-36. doi: 10.1038/mp.2013.152

Gobetz, G. E. (1967). Learning Mobility in Blind Children and the Geriatric Blind. Cleveland, OH: Cleveland Society of the Blind.

Green, J. S., Parfrey, P. S., Harnett, J. D., Farid, N. R., Cramer, B. C., Johnson, G., et al. (1989). The cardinal manifestations of Bardet-Biedl syndrome, a form of Laurence-Moon-Biedl syndrome. N Engl. J. Med. 321, 1002-1009. doi: 10.1056/NEJM198910123211503

Grøndahl, J., and Mjøen, S. (1986). Usher syndrome in four Norwegian counties. Clin. Genet. 30, 14-28. doi: 10.1111/j.1399-0004.1986.tb00564.x

Hahn, C., Lim, H. K., and Lee, C. U. (2014). Neuroimaging findings in late-onset schizophrenia and bipolar disorder. J. Geriatr. Psychiatry Neurol. 27, 56-62. doi: $10.1177 / 0891988713516544$

Hebb, A. O., and Ojemann, G. A. (2013). The thalamus and language revisited. Brain Lang. 126, 99-108. doi: 10.1016/j.bandl.2012.06.010

Horrobin, D. F. (1979). Schizophrenia: reconciliation of the dopamine, prostaglandin, and opioid concepts and the role of the pineal. Lancet 1, 529-531. doi: 10.1016/S0140-6736(79)90948-6

Hulshoff Pol, H. E., Schnack, H. G., Bertens, M. G., van Haren, N. E., van der Tweel, I., Staal, W. G., et al. (2002). Volume changes in gray matter in patients with schizophrenia. Am. J. Psychiatry 159, 244-250. doi: 10.1176/appi.ajp.159. 2.244

Hulshoff Pol, H. E., Schnack, H. G., Mandl, R. C., Cahn, W., Collins, D. L., Evans, A. C., et al. (2004). Focal white matter density changes in schizophrenia: reduced inter-hemispheric connectivity. Neuroimage 21, 27-35. doi: 10.1016/j.neuroimage.2003.09.026

Ishizuka, K., Kamiya, A., Oh, E. C., Kanki, H., Seshadri, S., Robinson, J. F., et al. (2011). DISC1-dependent switch from progenitor proliferation to migration in the developing cortex. Nature 473, 92-96. doi: 10.1038/nature09859

Jain, K. C., and Garg, A. R. (1981). Laurence-Moon-Biedl syndrome with schizophrenia (a case report). Indian J. Psychiatry 23, 270-271.

Jensen, L. J., Kuhn, M., Stark, M., Chaffron, S., Creevey, C., Muller, J., et al. (2009). STRING 8-a global view on proteins and their functional interactions in 630 organisms. Nucleic Acids Res. 37, D412-D416. doi: 10.1093/nar/gkn760

Kamiya, A., Kubo, K., Tomoda, T., Takaki, M., Youn, R., Ozeki, Y., et al. (2005). A schizophrenia-associated mutation of DISC1 perturbs cerebral cortex development. Nature Cell Biol. 7, 1167-1178. doi: 10.1038/ncb1328

Kanwisher, N., McDermott, J., and Chun, M. M. (1997). The fusiform face area: a module in human extrastriate cortex specialized for face perception. J. Neurosci. 17, 4302-4311.

Kay, D. W. K., and Roth, M. (1961). Environmental and hereditary factors in the schizophrenias of age ("late paraphrenia") and their bearing on the general problem of causation in schizophrenia. J. Ment. Sci. 107, 649-686. doi: 10.1192/bjp.107.449.649

Kerschbaumer, L. (1943). Endocrine maldevelopment in schizophrenia. J. Nerv. Ment. Dis. 98, 521-525. doi: 10.1097/00005053-194311000-00009

Kitada, R., Okamoto, Y., Sasaki, A. T., Kochiyama, T., Miyahara, M., Lederman, S. J., et al. (2013). Early visual experience and the recognition of basic facial expressions: involvement of the middle temporal and inferior frontal gyri during haptic identification by the early blind. Front. Hum. Neurosci. 7:7. doi: 10.3389/fnhum.2013.00007

Kleist, K. (1914). Aphasia and Geisteskrankheit. Münchener Medizinische Wochenschrift 61, 8-12.

Kong, L., Fry, M., Al-Samarraie, M., Gilbert, C., and Steinkuller, P. G. (2012). An update on progress and the changing epidemiology of causes of childhood blindness worldwide. J. AAPOS 16, 501-507. doi: 10.1016/j.jaapos.2012. 09.004

Landgraf, S., Amado, I., Berthoz, A., and van der Meer, E. (2012). Cognitive identity in schizophrenia: vision, space, and body perception from prodrome to syndrome. Curr. Psychiatry Rev. 8, 119-139. doi: 10.2174/1573400511208020119

Landgraf, S., Krebs, M. O., Olié, J. P., Committeri, G., van der Meer, E., Berthoz, A., et al. (2010). Real world referencing and schizophrenia: are we experiencing the same reality? Neuropsychologia 48, 2922-2930. doi: 10.1016/j.neuropsychologia.2010.05.034

Landgraf, S., and Osterheider, M. (2013). "To see or not to see: that is the question." The "Protection-Against-Schizophrenia" (PaSZ) model: evidence from congenital blindness and visuo-cognitive aberrations. Front. Psychol. 4:352. doi: 10.3389/fpsyg.2013.00352 
Lerner, I., Bentin, S., and Shriki, O. (2012). Excessive attractor instability accounts for semantic priming in schizophrenia. PLoS ONE 7:e40663. doi: 10.1371/journal.pone.0040663

Lewis, D. A., Curley, A. A., Glausier, J. R., and Volk, D. W. (2012). Cortical parvalbumin interneurons and cognitive dysfunction in schizophrenia. Trends Neurosci. 35, 57-67. doi: 10.1016/j.tins.2011.10.004

Llano, D. A. (2013). Functional imaging of the thalamus in language. Brain Lang. 126, 62-72. doi: 10.1016/j.bandl.2012.06.004

Martinez-Morales, J. R., Signore, M., Acampora, D., Simeone, A., and Bovolenta, P. (2001). Otx genes are required for tissue specification in the developing eye. Development 128, 2019-2030.

Matsunaga, E., Nambu, S., Oka, M., Okanoya, K., and Iriki, A. (2013). Comparative analysis of Protocadherin-11 X-linked expression among postnatal rodents, non-human primates, and songbirds suggests its possible involvement in brain evolution. PLOS ONE 8:e58840. doi: 10.1371/journal.pone. 0058840

McClellan, J. M., Susser, E., and King, M. C. (2007). Schizophrenia: a common disease caused by multiple rare alleles. Br. J. Psychiatry 190, 194-199. doi: 10.1192/bjp.bp.106.025585

McDonald, C., Kenna, P., and Larkin, T. (1998). Retinits pigmentosa and schizophrenia. Eur. Psychiatry 13, 423-426.

McKenna, P. J., and Oh, T. M. (2005). Schizophrenic Speech. Cambridge: Cambridge University Press.

Moore, S. J., Green, J. S., Fan, Y., Bhogal, A. K., Dicks, E., Fernandez, B. A., et al. (2005). Clinical and genetic epidemiology of Bardet-Biedl syndrome in Newfoundland: A 22-year prospective, population-based, cohort study. Am. J. Med. Genet. 132A, 352-360. doi: 10.1002/ajmg.a.30406

O’Mahony, P. F. (1954). Laurence-Moon-Biedl syndrome. Endocrinology 18:583.

Ogden, T. H. (1982). Projective Identification and Psychotherapeutic Technique. Northvale, NJ: Jason Aronson.

Orr, J. M., Turner, J. A., and Mittal, V. A. (2014). Widespread brain dysconnectivity associated with psychotic-like experiences in the general population. Neuroimage Clin. 4, 343-351. doi: 10.1016/j.nicl.2014.01.006

Pascual-Leone, A., Amedi, A., Fregni, F., and Merabet, L. B. (2005). The plastic human brain cortex. Annu. Rev. Neurosci. 28, 377-401. doi: 10.1146/annurev.neuro.27.070203.144216

Pascual-Leone, A., and Hamilton, R. (2001). The metamodal organization of the brain. Prog. Brain Res. 134, 427-445. doi: 10.1016/S0079-6123(01) 34028-1

Perez-Pereira, M., and Conti-Ramsden, G. (1999). Social Interaction and Language Development in Blind Children. Hove: Psychology Press.

Pinault, D. (2011). Dysfunctional thalamus-related networks in schizophrenia. Schizophr. Bull. 37, 238-243. doi: 10.1093/schbul/sbq165

Pollex, R. L., and Hegele, R. A. (2004). Hutchinson-Gilford progeria syndrome. Clin. Genet. 66, 375-381. doi: 10.1111/j.1399-0004.2004.00315.x

Postmes, L., Sno, H. N., Goedhart, S., van der Stel, J., Heering, H. D., and de Haan, L. (2014). Schizophrenia as a self-disorder due to perceptual incoherence. Schizophr. Res. 152, 41-50. doi: 10.1016/j.schres.2013.07.027

Priddle, T. H., and Crow, T. J. (2009). The protocadherin $11 \mathrm{X} / \mathrm{Y}$ gene pair as a putative determinant of cerebral dominance in Homo sapiens. Future Neurol. 4, 509-518. doi: 10.2217/fnl.09.23

Priddle, T. H., and Crow, T. J. (2013). Protocadherin 11X/Y a human-specific gene pair: an immunohistochemical survey of fetal and adult brains. Cereb. Cortex 23, 1933-1941. doi: 10.1093/cercor/bhs181

Purushothaman, G., Marion, R., Li, K., and Casagrande, V. A. (2012). Gating and control of primary visual cortex by pulvinar. Nat. Neurosci. 15, 905-912. doi: 10.1038/nn.3106

Resnikoff, S., Pascolini, D., Etya'ale, D., Kocur, I., Pararajasegaram, R., Pokharel, G. P., et al. (2004). Global data on visual impairment in the year 2002. Bull. World Health Organ. 82, 844-851.

Riscalla, L. M. (1980). Blindness and schizophrenia. Med. Hypotheses 6, 1327-1328. doi: 10.1016/0306-9877(80)90119-X

Robinson, D. L., and Petersen, S. E. (1992). The pulvinar and visual salience. Trends Neurosci. 15, 127-132.

Robinson, G. C., Jan, J. E., and Kinnis, C. (1987). Congenital ocular blindness in children, 1945 to 1984. Am. J. Dis. Child 141, 1321-1324.

Roder, B., Stock, O., Bien, S., Neville, H., and Rosler, F. (2002). Speech processing activates visual cortex in congenitally blind humans. Eur. J. Neurosci. 16, 930-936. doi: 10.1046/j.1460-9568.2002.02147.x
Roussos, P., and Haroutunian, V. (2014). Schizophrenia: susceptibility genes and oligodendroglial and myelin related abnormalities. Front. Cell. Neurosci. 8:5 doi: 10.3389/fncel.2014.00005

Rüsch, N., Spoletini, I., Wilke, M., Bria, P., Di Paola, M., Di Iulio, F., et al. (2007). Prefrontal-thalamic-cerebellar gray matter networks and executive functioning in schizophrenia. Schizophr Res. 93, 79-89. doi: 10.1016/j.schres. 2007.01.029

Sadato, N., Pascual-Leone, A., Grafman, J., Deiber, M. P., Ibañez, V., and Hallett, M. (1998). Neural networks for Braille reading by the blind. Brain 121, 1213-1229.

Sadato, N., Pascual-Leone, A., Grafman, J., Ibañez, V., Deiber, M. P., and Dold, G., et al. (1996). Activation of the primary visual cortex by Braille reading in blind subjects. Nature 380, 526-528.

Sanders, G. S., Gallup, G. G., Heinsen, H., Hof, P. R., and Schmitz, C. (2002). Cognitive deficits, schizophrenia, and the anterior cingulate cortex. Trends Cogn. Sci. 6, 190-192. doi: 10.1016/S1364-6613(02)01892-2

Sanders, G. S., Platek, S. M., and Gallup, G. G. (2003). No blind schizophrenics: are NMDA-receptor dynamics involved? Behav. Brain Sci. 26:103. doi: 10.1017/S0140525X03420025

Scholpp, S., and Lumsden, A. (2010). Building a bridal chamber: development of the thalamus. Trends Neurosci. 33, 373-380. doi: 10.1016/j.tins.2010.05.003

Schultz, C. C., Wagner, G., Koch, K., Gaser, C., Roebel, M., Schachtzabel, C., et al. (2013). The visual cortex in schizophrenia: alterations of gyrification rather than cortical thickness-a combined cortical shape analysis. Brain Struct. Funct. 218, 51-58. doi : 10.1007/s00429-011-0374-1

Sharfstein, S. R., Gordon, M. F., Libman, R. B., and Malkin, E. S. (1999). AdultOnset MELAS presenting as herpes encephalitis. Arch. Neurol. 56, 241-243.

Sharma, Y. R., Reddy, P. R. R. R., and Singh, D. V. (2004). Retinitis pigmentosa and allied disorders. JK Sci. 6, 115-120.

Shukla, G. D., Jain, B. S., Bajpai, H. S., and Mishra, D. N. (1983). Schizophrenia associated with retinitis pigmentosa: a case report. Indian J. Psychiatry 25, $162-163$.

Siekmeier, P. J., and Hoffman, R. E. (2002). Enhanced semantic priming in schizophrenia: a computer model based on excessive pruning of local connections in association cortex. Br. J. Psychiatry 180, 345-350. doi: 10.1192/bjp.180.4.345

Silverstein, S. M., and Keane, B. P. (2011a). Perceptual organization impairment in schizophrenia and associated brain mechanisms: review of research from 2005 to 2010. Schizophr. Bull. 37, 690-699. doi: 10.1093/schbul/sbr052

Silverstein, S. M., and Keane, B. P. (2011b). Vision science and schizophrenia research: toward a re-view of the disorder. Editors' introduction to special section. Schizophr. Bull. 37, 681-689. doi: 10.1093/schbul/sbr053

Silverstein, S. M., Wang, Y., and Keane, B. P. (2013a). Cognitive and neuroplasticity mechanisms by which congenital or early blindness may confer a protective effect against schizophrenia. Front. Psychol. 3:624. doi: 10.3389/fpsyg.2012.00624

Silverstein, S. M., Wang, Y., and Rochel, M. W. (2013b). Base rates, blindness, and schizophrenia. Front. Psychol. 4:157. doi: 10.3389/fpsyg.2013.00157

Skuse, D. (2006). Genetic influences on the neural basis of social cognition. Philos. Trans. R. Soc. Lond. B Biol. Sci. 361, 2129-2141. doi: 10.1098/rstb.2006.1935

Smith, M. J., Wang, L., Cronenwett, W., Mamah, D., Barch, D. M., and Csernansky, J. G. (2011). Thalamic morphology in schizophrenia and schizoaffective disorder. J. Psychiatr. Res. 45, 378-385. doi: 10.1016/j.jpsychires.2010. 08.003

Sonavane, S., Bambole, V., Bang, A., Shah, N., and Andrade, C. (2012). Continuation of ECT after recovery from transient, ECT-induced, postictal cortical blindness. J. ECT 28, 48-49. doi: 10.1097/YCT.0b013e318223c08

Steinkuller, P. G., Du, L., Gilbert, C., Foster, A., Collins, M. L., and Coats, D. K. (1999). Childhood blindness. J. AAPOS 3, 26-32.

Stewart, R. H., and Sardo, R. (1965). The psychotherapy of a blind schizophrenic child. J. Am. Acad. Child Psychiatry 4, 123-132. doi: 10.1016/S0002-7138(09) 62073-2

Sugiyama, S., Di Nardo, A. A., Aizawa, S., Matsuo, I., Volovitch, M., Prochiantz, A., et al. (2008). Experience-dependent transfer of Otx2 homeoprotein into the visual cortex activates postnatal plasticity. Cell 134, 508-520. doi: 10.1016/j.cell.2008.05.054

Sullivan, L. S., Bowne, S. J., Birch, D. G., Hughbanks-Wheaton, D., Heckenlively, J. R., Lewis, R. A., et al. (2006). Prevalence of disease-causing mutations in families with autosomal dominant retinitis pigmentosa: a screen of known genes in 200 families. Invest. Ophthalmol. Vis. Sci. 47, 3052-3064. doi: 10.1167/iovs.05-1443 
Szklarczyk, D., Franceschini, A., Kuhn, M., Simonovic, M., Roth, A., Mínguez, P., et al. (2011). The STRING database in 2011: functional interaction networks of proteins, globally integrated and scored. Nucleic Acids Res. 39, D561-D568. doi: 10.1093/nar/gkq973

Tandon, R., Heckers, S., Bustillo, J., Barch, D. M., Gaebel, W., Gur, R. E., et al. (2013). Catatonia in DSM-5. Schizophr. Res. 150, 26-30. doi: 10.1016/j.schres.2013.04.034

Thong, J. Y. J., Qiu, A., Sum, M. Y., Kuswanto, C. N., Tuan, T. A., Donohoe, G., et al. (2013). Effects of the neurogranin variant rs12807809 on thalamocortical morphology in schizophrenia. PLOS ONE 8:e85603. doi: 10.1371/journal.pone.0085603

Uhlhaas, P. J., and Silverstein, S. M. (2005). Perceptual organization in schizophrenia spectrum disorders: empirical research and theoretical implications. Psychol. Bull. 131, 618-632. doi: 10.1037/0033-2909.131. 4.618

Watson, A. R., Defterali, Ç., Bak, T. H., Sorace, A., McIntosh, A. M., Owens, D. G. C., et al. (2012). Use of second-person pronouns and schizophrenia. Br. J. Psychiatry 200, 342-343. doi: 10.1192/bjp.bp.111.095448

Weiss, M., Meshulam, B., and Wijsenbeek, H. (1981). The possible relationship between Laurence-Moon-Biedl-Bardet syndrome and a schizophrenic-like psychosis. J.Nerv. Ment. Dis. 169, 259-260.
Yoon, J. H., Sheremata, S. L., Rokem, A., and Silver, M. A. (2013). Windows to the soul: vision science as a tool for studying biological mechanisms of information processing deficits in schizophrenia. Front. Psychol. 4:681. doi: 10.3389/fpsyg.2013.00681

Conflict of Interest Statement: The authors declare that the research was conducted in the absence of any commercial or financial relationships that could be construed as a potential conflict of interest.

Received: 22 July 2014; accepted: 04 November 2014; published online: 28 November 2014.

Citation: Leivada E and Boeckx C (2014) Schizophrenia and cortical blindness: protective effects and implications for language. Front. Hum. Neurosci. 8:940. doi: 10.3389/ fnhum.2014.00940

This article was submitted to the journal Frontiers in Human Neuroscience.

Copyright (C) 2014 Leivada and Boeckx. This is an open-access article distributed under the terms of the Creative Commons Attribution License (CC BY). The use, distribution or reproduction in other forums is permitted, provided the original author(s) or licensor are credited and that the original publication in this journal is cited, in accordance with accepted academic practice. No use, distribution or reproduction is permitted which does not comply with these terms. 